\title{
Calibration of a multi-anvil high-pressure apparatus to simulate planetary interior conditions
}

\author{
J. S. Knibbe ${ }^{1 *}$ D, S. M. Luginbühl ${ }^{1}$, R. Stoevelaar ${ }^{1}$, W. van der Plas ${ }^{1}$, D. M. van Harlingen ${ }^{1}$, N. Rail, E. S. Steenstra ${ }^{1}$, \\ R. van de Geer ${ }^{1}$ and W. van Westrenen ${ }^{1}$
}

\footnotetext{
* Correspondence: j.s.knibbe@vu.nl ${ }^{1}$ Faculty of Science, Vrije Universiteit Amsterdam, Amsterdam, the Netherlands

Full list of author information is available at the end of the article
}

\begin{abstract}
This paper presents the setup and pressure calibration of an 800-ton multi-anvil apparatus installed at the Vrije Universiteit (Amsterdam, the Netherlands) to simulate pressure-temperature conditions in planetary interiors. This high-pressure device can expose cubic millimeter sized samples to near-hydrostatic pressures up to $\sim 10 \mathrm{GPa}$ and temperatures exceeding $2100{ }^{\circ} \mathrm{C}$. The apparatus is part of the Distributed Planetary Simulation Facility (DPSF) of the EU Europlanet 2020 Research Infrastructure, and significantly extends the pressure-temperature range that is available through international access to this facility.
\end{abstract}

Keywords: High pressure, Multi-anvil, Experimental petrology, Planetary interiors

\section{Introduction}

A fundamental problem hampering studies of the composition and structure of the terrestrial planets is that most of their mass is located at depths inaccessible to direct investigation. The occurrence and behavior of solid and molten silicate and metal phases at ambient pressures are relatively well constrained due to analyses of natural surface samples. For Earth, some additional insights into the chemical properties of the deeper subsurface can be obtained indirectly from analyses of natural samples of deep origin, such as extrusive volcanic rocks formed by partial melting of planetary mantles and magmatic minerals from deeper levels entrained in such rocks during their transport to the surface (e.g., [1-4]), high-pressure metamorphic rocks formed at great depths but subsequently exhumed to the surface in mountain belts (e.g. [5]), and the study of mineral inclusions in diamonds formed hundreds of kilometers underneath the surface (e.g., [3]). Seismology can also provide a window into the physical and chemical properties of planetary interiors but is currently limited to studies of the Earth (e.g. [6-8]) and the Moon (e.g. $[9,10])$. Interior models for other planets and moons in the solar system are constrained by remote sensing and geodesic data obtained by space missions (e.g., [11-14]).

Correct interpretation of measured planetary characteristics for interior models relies on the understanding of high-pressure and high-temperature phase mineralogy. With the use of physical and chemical laws which govern the crystal structure of minerals,

(c) The Author(s); licensee Springer on behalf of EPJ. 2018 Open Access This article is distributed under the terms of the Creative Commons Attribution 4.0 International License (http://creativecommons.org/licenses/by/4.0/), which permits unrestricted use, distribution, and reproduction in any medium, provided you give appropriate credit to the original author(s) and the source, provide a link to the Creative Commons license, and indicate if changes were made. 
e.g. thermodynamic relations and density functional theory, ambient-condition crystalline properties can be extrapolated to high pressures and high-pressure phases can be predicted (e.g. $[15,16])$. However, such methods become computationally expensive and impractical for systems containing numerous elements, and have difficulties in predicting material properties in the high-temperature regime of deep planetary interiors.

Experimental techniques that expose samples to high pressures and temperatures provide crucial complementary constraints on the matter of planetary interiors. For interior pressures to a maximum of approximately 3.5-4 GPa, a so-called piston cylinder press can be used to compress cubic millimeter sized natural or synthetic rock samples while simultaneously heating the samples to a maximum of approximately $1650{ }^{\circ} \mathrm{C}$ (e.g. [17]). Two such piston-cylinder apparati at Vrije Universiteit Amsterdam, the Netherlands, are currently part of the Distributed Planetary Simulation Facility (DPSF) of the EU Europlanet 2020 Research Infrastructure, providing access to European planetary scientists interested in using this technique. Facilities that can achieve higher pressures relevant for Earth's upper mantle and the deep interiors of the Moon, Mercury, Mars and Ganymede would help expand the opportunities of this scientific community.

Here, we present the experimental setup and assembly pressure calibration of an 800 ton multi-anvil apparatus at the Vrije Universiteit Amsterdam, the Netherlands. This press can expose cubic millimeter-sized samples to pressures up to $\sim 10 \mathrm{GPa}$ and temperatures up to $\sim 2100{ }^{\circ} \mathrm{C}$ with the assembly used in this study and significantly extends the pressure-temperature range that is available through international access to this facility.

Since the first introduction of multi-anvil presses more than half a century ago, developments of this type of presses have significantly improved their experimental reproducibility, extended the attainable pressure and temperature range, and hence expanded the corresponding research opportunities [18]. Although multi-anvil apparati are widely used for examining the physical and chemical characteristics of planetary materials, details of their calibration are rarely published, hampering full comparison of results obtained at different facilities. Here, we present full details of the calibration of the device, including an assessment of uncertainties.

\section{Methods/Experimental}

\section{Experimental setup}

The 800 ton hydraulic press was built by the workshop of the Department of Earth Sciences at the University of Bristol, UK. The apparatus contains a Walker-type pressure module [19] with a $15 \mathrm{~cm}$ tall, $20 \mathrm{~cm}$ inner diameter, and $6.3 \mathrm{~cm}$ thick hardened steel wall that rests on an oil vessel. The module holds anvils in a Kawai geometry [20], consisting of six hardened steel outer wedges and eight cubic-inch-sized tungsten carbide (WC) inner anvils (grade THM-U, Kennametal, Arnhem, the Netherlands). A hardened steel module lid rests on the top three wedges and closes the module. An hydraulic pumping system regulates the pressure in the oil vessel, which controls the pressure in the module generated by pressing the module upward against a steel ceiling (Fig. 1). Mylar sheets $(0.1 \mathrm{~mm}$ thickness), lubricated with polytetrafluorethylene (PTFE) spray, line the inner wall of the module and the outer surfaces of the outer wedges to reduce 


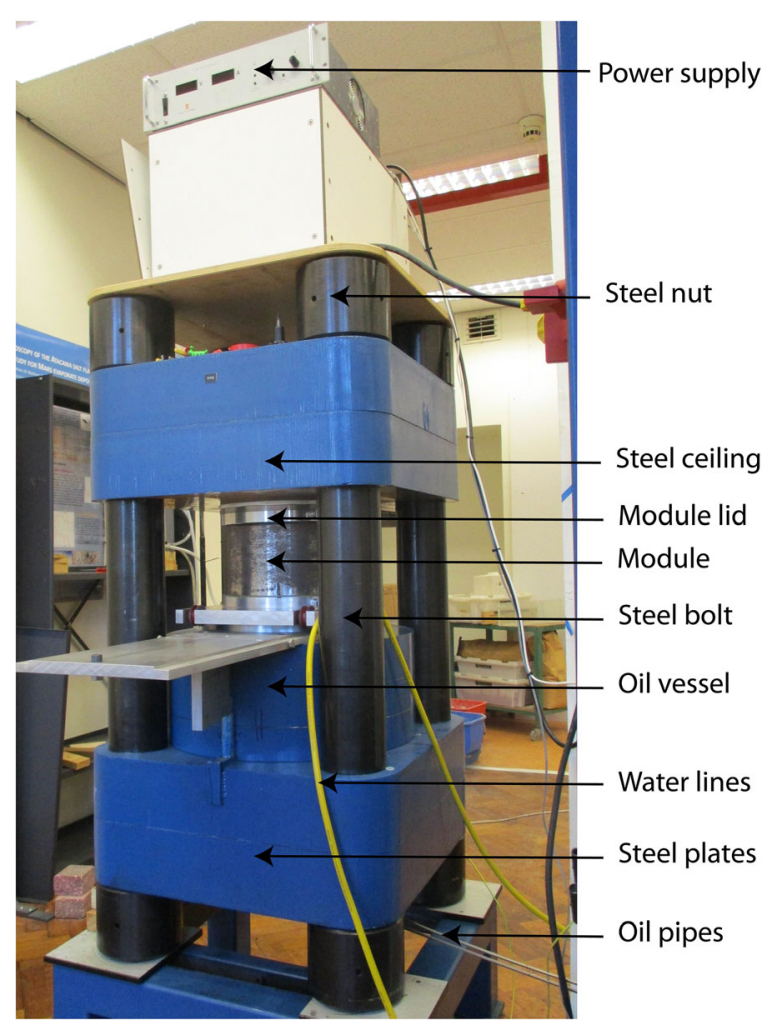

Fig. 1 The multi-anvil apparatus at Vrije Universiteit Amsterdam

friction and prevent electrical conductance between the wedges and the module wall [19]. All inner anvils have one truncated corner with $11 \mathrm{~mm}$ edge length (TEL = truncated edge length $=11 \mathrm{~mm}$ ). They are cubically assembled and enclose an octahedral sample assembly with $18 \mathrm{~mm}$ edge lengths $(\mathrm{OEL}=$ octahedron edge length $=18 \mathrm{~mm}$ ), leaving $\sim 3.4 \mathrm{~mm}$ space in between the anvils (Fig. 2). Pyrophyllite gaskets of 3.3/ $3.0 \mathrm{~mm}$ height/width are placed between the inner anvils near the truncated edges to prevent contact between inner anvils and prohibit outward flow of the sample assembly's pressure medium during compression. PTFE tape is placed snugly against the back

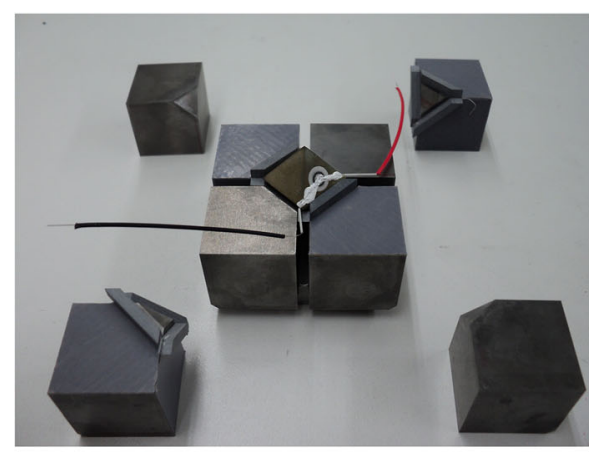

a

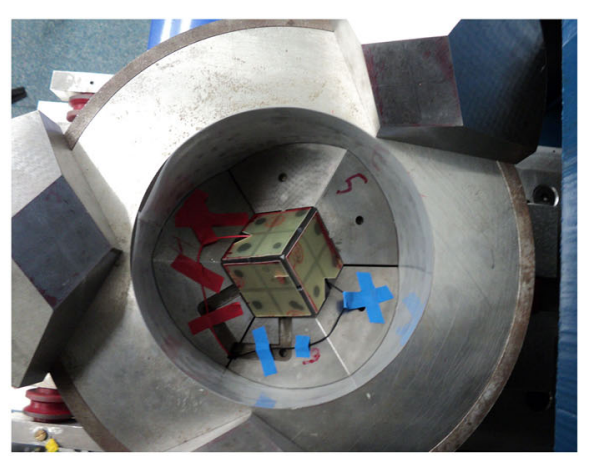

b

Fig. 2 The experimental setup: a the assembly within the eight tungsten inner anvils. $\mathbf{b}$ The pressure module with outer anvils surrounding the cube of inner anvils 
of the gaskets to minimize extrusion of these gaskets during compression. The cubically assembled inner anvils are covered and held together by sheets of epoxy resin fiberglass (known as G10 sheets, $0.65 \mathrm{~mm}$ thickness) glued on each side of the cubic assemble. These G10 sheets also prevent electrical conductance between the inner anvils and the outer wedges. Two copper foils are placed through cuts in the G10 sheets and electrically connect the bottom inner anvil with one of the lower wedges and the top inner anvil with one of the upper wedges. These yield electrically connected paths from the bottom octahedral surface to the module bottom plate and from the top octahedral surface to the module top plate, via the inner anvils, copper and wedges.

The sample assembly (Fig. 3) is a $\mathrm{Cr}_{2} \mathrm{O}_{3}$-doped $\mathrm{MgO}$ octahedron $(95 \% \mathrm{MgO}$ and $5 \%$ $\mathrm{Cr}_{2} \mathrm{O}_{3}$ with $30 \%$ porosity, from Japan Ceramic Engineering Co., Ltd.), with a $7 \mathrm{~mm}$ diameter central hole [21]. A zirconia $\left(\mathrm{ZrO}_{2}\right)$ sleeve of $4 \mathrm{~mm}$ inner diameter (drilled out of plates from Mino Yogyo Ceramics, Japan) is placed in the hole and acts as heat insulator for its interior. The assembly set-up interior to the $\mathrm{ZrO}_{2}$ sleeve varies depending on the type of experiment. In this study, sample pressures are calibrated with respect to the vessel's oil pressure by identifying and bracketing known high-pressure phase transitions. Electrical resistance measurements at room temperature are performed to detect high-pressure transitions in metals in situ. High-temperature quench (ex situ) experiments are performed to bracket high-pressure phase transitions in silica $\left(\mathrm{SiO}_{2}\right)$ and in calcium germinate $\left(\mathrm{CaGeO}_{3}\right)$.

For experiments that measure electrical resistance of a sample at room temperature, the $\mathrm{ZrO}_{2}$ sleeve contains two $\mathrm{MgO}$ rods that squeeze a sample of thin needle-like dimensions at the assembly's centre. Two copper ribbons are placed along the outside of the $\mathrm{MgO}$ rods to electrically connect the sample with the two opposite surfaces of the octahedral assembly and close the electrical path from the top to the bottom of the module trough the sample (Fig. 3a). An ohmmeter measures the electrical resistance between the top and bottom of the module in situ during sample compression.

For high-temperature quench (ex situ) experiments, a graphite sleeve with $3.6 \mathrm{~mm}$ inner diameter is placed inside the zirconia and closes the electrical path from the top of the module to the bottom. A $2 \mathrm{~mm}$ long graphite sample bucket with a $1 \mathrm{~mm}$ thick lid contains the sample powder and is placed in the middle of the assembly, encapsulated by crushable polycrystalline MgO parts (Fig. 3b). Type C ( $\mathrm{W}_{95} \operatorname{Re}_{5}$ and $\left.\mathrm{W}_{74} \operatorname{Re}_{26}\right)$ thermocouple wires are guided through alumina tubes to the sample and create a junction just above the sample container. An electrical voltage is applied by a DC power

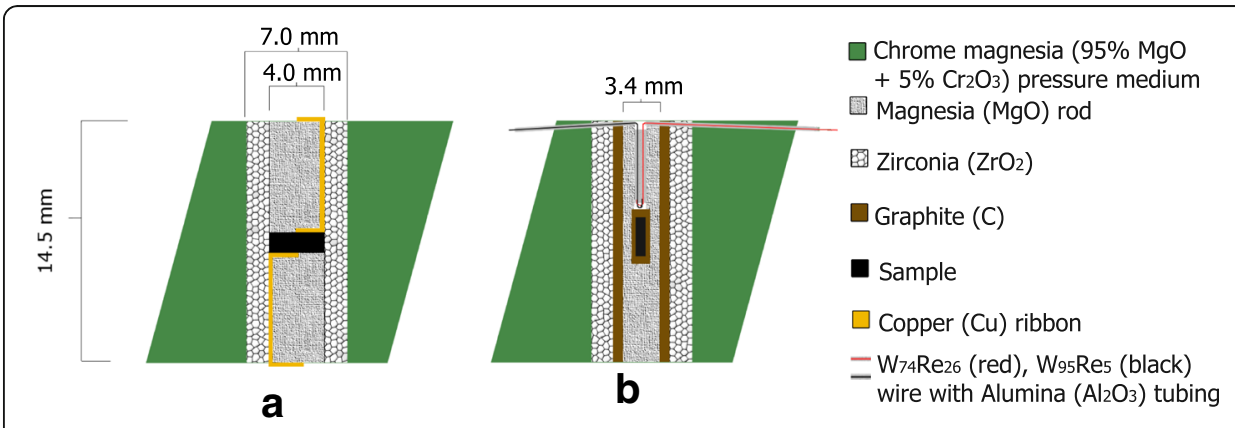

Fig. 3 Schematic assembly setup for the performed calibration experiments. a The 18/11 OEL/TEL assembly for room temperature calibration experiments. b The 18/11 OEL/TEL assembly for high temperature calibration experiments 
supply (Delta Elektronica) between the top and bottom of the module to heat the sample environment by the ohmic dissipation in the graphite cylinder. The temperature difference between the thermocouple junction and the ends of the thermocouple wires induces a voltage at the thermocouple ends (the Seebeck effect). We measure this voltage and relate it to sample temperature using the ASTM E230/E230M standard from the National Institute of Standards and Technology (NIST).

\section{Starting materials and phase transitions}

Room temperature resistance measurements are performed on metallic bismuth (Bi) samples (Alfa Aesar, 99.999\% purity). Bismuth phase transitions from trigonal to monoclinic (Bi I-II) at $2.55 \pm 0.006 \mathrm{GPa}$, from monoclinic to tetragonal (Bi II-III) at $2.69 \pm$ $0.01 \mathrm{GPa}$, and from tetragonal to body-centered cubic (Bi III-V) at $7.66 \pm 0.18 \mathrm{GPa}$ are historically well studied by a variety of methods including detecting changes in sample volume, shock measurements, detecting variations in electrical resistance and by crystal structure measurements using in-situ X-ray diffraction ([22]; and references therein). We identify the phase transitions by detecting characteristic variations in the measured electrical resistance during compression.

High temperature quench experiments are performed with $\mathrm{CaGeO}_{3}$ (synthesized to wollastonite structure) and hydrated $\mathrm{SiO}_{2}$ (Qtz structure) (Alfa Aesar) sample powders. At $1200{ }^{\circ} \mathrm{C}$, a phase transition in $\mathrm{SiO}_{2}$ from trigonal $(\alpha-)$ quartz to monoclinic coesite takes place at $3.2 \pm 0.1 \mathrm{GPa}$ [23-29]. At $1300{ }^{\circ} \mathrm{C}$, a phase transition from monoclinic coesite to tetragonal stishovite takes place in $\mathrm{SiO}_{2}$ at $9.4 \pm 0.4 \mathrm{GPa}$ [23, 29-35]. At $1000{ }^{\circ} \mathrm{C}$, a phase transition in $\mathrm{CaGeO}_{3}$ from tetragonal garnet to orthorhombic perovskite occurs at $6.2 \pm 0.2 \mathrm{GPa}$ [36-41].

\section{Experimental procedure and sample analysis}

After loading the sample assembly, pressure is increased at a rate of 20 bar per hour for high-temperature experiments and 10 bar per hour for room temperature experiments. For the latter, electrical resistance is measured continuously during this compression stage. After the target pressure is attained, high-temperature experiments are heated at a rate of $50{ }^{\circ} \mathrm{C}$ per minute to the target temperature. Temperature is held constant at the target value for a minimum of $30 \mathrm{~min}$ and up to a few hours. Samples are quenched by switching off the electrical power. When the experiment is finished, i.e. after target pressure is achieved for a room temperature experiment or when the module is cooled down to below $50{ }^{\circ} \mathrm{C}$ after a high-temperature experiment, pressure is reduced by 10 bar per hour to ambient conditions.

Quenched samples are embedded in a 1 in. epoxy mount and ground with alumina paper until the sample surface is exposed. We collected Raman spectra from these samples to determine the sample's mineralogy using a red $(785 \mathrm{~nm})$ laser on a Renishaw InVia Reflex confocal Raman microscope at Vrije Universiteit Amsterdam with a grating of 1200 grooves $/ \mathrm{mm}$.

\section{Results}

\section{Sample analysis}

The electrical resistance measured in-situ through a $\mathrm{Bi}$ sample during a room temperature, high-pressure experiment is plotted in Fig. 4. The detected variations in 
electrical resistance identify the Bi I-II phase transition at an oil pressure of $89 \mathrm{bar}$, the Bi II-III phase transition at an oil pressure of 108 bar, and the Bi III-V phase transition at an oil pressure of 313 bar. These transitions are used as a first-order indication for the relation between sample pressure and oil pressure at high temperatures.

Raman spectra of quenched $\mathrm{SiO}_{2}$ samples, obtained from high-temperature quench experiments listed in Table 1, are shown in Fig. 5. Experiments MA16 and MA11 with oil pressures at 130 bar and 135 bar bracket the disappearance of quartz peaks at $206 \mathrm{~cm}^{-1}$ and $\sim 464 \mathrm{~cm}^{-1}$ and the appearance of coesite peaks at $\sim 270 \mathrm{~cm}^{-1}$ and $\sim$ $520 \mathrm{~cm}^{-1}$. Experiments MA31 and MA33 with oil pressures at 390 bar and 420 bar bracket the disappearance of $\sim 270 \mathrm{~cm}^{-1}$ and $\sim 520 \mathrm{~cm}^{-1}$ peaks and the appearance of stishovite peaks at $\sim 230 \mathrm{~cm}^{-1}$ and $\sim 752 \mathrm{~cm}^{-1}$.

Raman spectra of quenched $\mathrm{CaGeO}_{3}$ samples, obtained from high-temperature quench experiments listed in Table 1, are shown in Fig. 6. Both experiments MA30 at $255 \mathrm{GPa}$ and MA23 at $260 \mathrm{GPa}$ show clear garnet-structured peaks at $508 \mathrm{~cm}^{-1}$ and $805 \mathrm{~cm}^{-1}$ [40], which are absent in samples that were quenched at higher pressure. The perovskite-structure peak at $284 \mathrm{~cm}^{-1}$ [42] is present in MA23 and all samples that were quenched at higher pressure. The Raman spectrum of MA23 contains both the garnet and perovskite structure signatures and marks the location of the phase transition. Sample MA28, also obtained from an experiment at 260 bar, does not show any Raman signature for garnet. We go into more detail on this issue in the discussion section.

\section{Calibration curve}

We obtain a pressure calibration curve by spline interpolation. The Bi phase transitions are not used in the interpolation, because they have been identified at room temperature whereas we are interested in the pressure calibration at high temperatures. Figure 7 plots the pressure calibration curve, of which Table 2 lists consecutive 0.5 GPa sample pressure points.

\section{Discussion}

\section{Temperature errors}

The temperature distribution in high-pressure assemblies is known to be heterogeneous in axial and radial dimensions. In our experiments, temperature is measured by

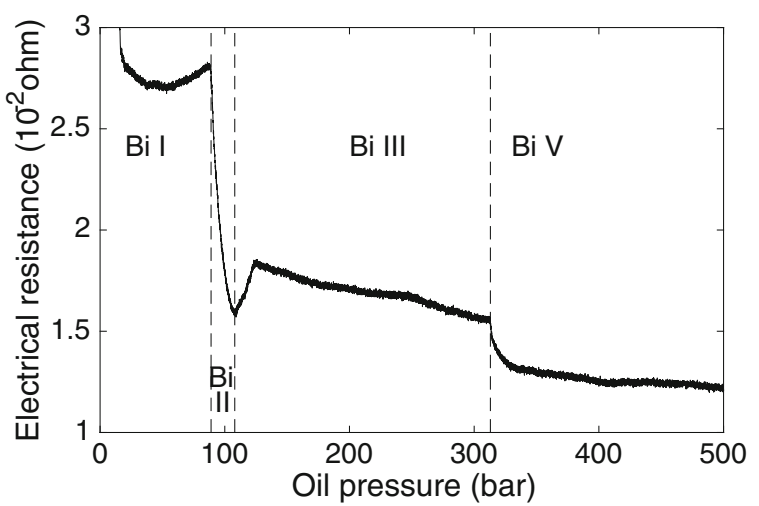

Fig. 4 Electrical resistance of bismuth (Bi) measured in-situ during a high pressure experiment at room temperature 
Table $1{ }^{\text {a }}$ Thermocouple readout failed in these experiments. These temperatures have been estimated based on the power-temperature relationship of other experiments at similar pressures and carry an uncertainty of \pm 150 degrees

\begin{tabular}{lllllll}
\hline Experiment & $\begin{array}{l}\text { Starting } \\
\text { Composition }\end{array}$ & $\begin{array}{l}\text { Oil pressure } \\
(\text { bar })\end{array}$ & $\begin{array}{l}\text { Power } \\
(\mathrm{W})\end{array}$ & $\begin{array}{l}\text { Temperature } \\
\left({ }^{\circ} \mathrm{C}\right)\end{array}$ & $\begin{array}{l}\text { Duration } \\
\text { (hr:min) }\end{array}$ & $\begin{array}{l}\text { Resulting } \\
\text { polymorph }\end{array}$ \\
\hline MA2 & $\mathrm{SiO}_{2}$ & 240 & 700 & $1100^{\mathrm{a}}$ & $3: 00$ & Coe \\
MA4 & $\mathrm{SiO}_{2}$ & 300 & 500 & $750^{\mathrm{a}}$ & $2: 50$ & Coe \\
MA5 & $\mathrm{SiO}_{2}$ & 175 & 500 & $750^{\mathrm{a}}$ & $3: 30$ & Coe \\
MA6 & $\mathrm{SiO}_{2}$ & 175 & 844 & 1100 & $1: 50$ & Coe \\
MA7 & $\mathrm{SiO}_{2}$ & 150 & 773 & 1200 & $3: 30$ & Coe \\
MA8 & $\mathrm{SiO}_{2}$ & 100 & 805 & $1200^{\mathrm{a}}$ & $2: 00$ & Qtz \\
MA9 & $\mathrm{SiO}_{2}$ & 125 & 755 & $1200^{\mathrm{a}}$ & $1: 00$ & Qtz \\
MA11 & $\mathrm{SiO}_{2}$ & 135 & 766 & 1200 & $3: 30$ & Coe \\
MA13 & $\mathrm{SiO}_{2}$ & 110 & 682 & 1200 & $5: 00$ & Qtz \\
MA14 & $\mathrm{SiO}_{2}$ & 125 & 665 & $1200^{\mathrm{a}}$ & $2: 00$ & Qtz \\
MA15 & $\mathrm{SiO}_{2}$ & 125 & 674 & 1200 & $2: 00$ & Qtz \\
MA16 & $\mathrm{SiO}_{2}$ & 130 & 717 & 1200 & $6: 00$ & Qtz \\
MA23 & $\mathrm{CaGeO}_{3}$ & 260 & 574 & $950^{\mathrm{a}}$ & $1: 30$ & Grt + Prv \\
MA24 & $\mathrm{CaGeO}_{3}$ & 300 & 695 & $1000^{\mathrm{a}}$ & $1: 35$ & Prv \\
MA25 & $\mathrm{CaGeO}_{3}$ & 280 & 667 & $1000^{\mathrm{a}}$ & $1: 10$ & Prv \\
MA26 & $\mathrm{CaGeO}_{3}$ & 270 & 742 & 1000 & $1: 20$ & Prv \\
MA27 & $\mathrm{CaGeO}_{3}$ & 265 & 651 & 1000 & $1: 30$ & Prv \\
MA28 & $\mathrm{CaGeO}_{3}$ & 260 & 895 & 1000 & $1: 00$ & Prv \\
MA29 & $\mathrm{CaGeO}_{3}$ & 263 & 650 & $1000^{\mathrm{a}}$ & $1: 00$ & Prv \\
MA30 & $\mathrm{CaGeO}_{3}$ & 255 & 670 & $1000^{\mathrm{a}}$ & $1: 05$ & Grt \\
MA31 & $\mathrm{SiO}_{2}$ & 390 & 982 & 1300 & $0: 30$ & Coe \\
MA33 & $\mathrm{SiO}_{2}$ & 420 & 878 & 1300 & $1: 00$ & Stv \\
\hline
\end{tabular}

a thermocouple at the wire-junction just outside the graphite sample container, approximately $1.5 \mathrm{~mm}$ away from the center of the assembly and sample. For an indication on the temperature difference between the sample and the thermocouple junction as well as the extent of thermal heterogeneity, we have modelled the temperature distribution in our assembly using the numerical method of Hernlund et al. [43]. The temperature distribution in the assembly is assumed to be axisymmetric about the central axis of the assembly (the $r=0$ line) and symmetric about the assembly's horizontal mid-plane (the $\mathrm{z}=0$ plane), where zero heat flux boundary conditions are applied. Constant temperature boundary conditions are applied at $\mathrm{z}=11 \mathrm{~mm}$ and $r=11 \mathrm{~mm}$ of un-prescribed value, which is interior to the WC cubes and far from the assembly's center. We used the model setting that accounts for the effect of the surrounding module, which prescribes a constant boundary temperature of $25{ }^{\circ} \mathrm{C}$ several hundreds of millimetres away from the sample [43]. A thermocouple temperature of $1200{ }^{\circ} \mathrm{C}$ was assumed.

The results indicate that temperatures interior to the graphite heater vary most strongly in axial direction (Fig. 8). This temperature gradient is small interior to the graphite sample container $(\mathrm{z}<1.5 \mathrm{~mm})$, because graphite has a high thermal conductivity. The temperature at the thermocouple junction (at $\mathrm{z}=1.5$ ), is only six degrees below the central temperature of $1200{ }^{\circ} \mathrm{C}$ according to this numerical model. These modelled 


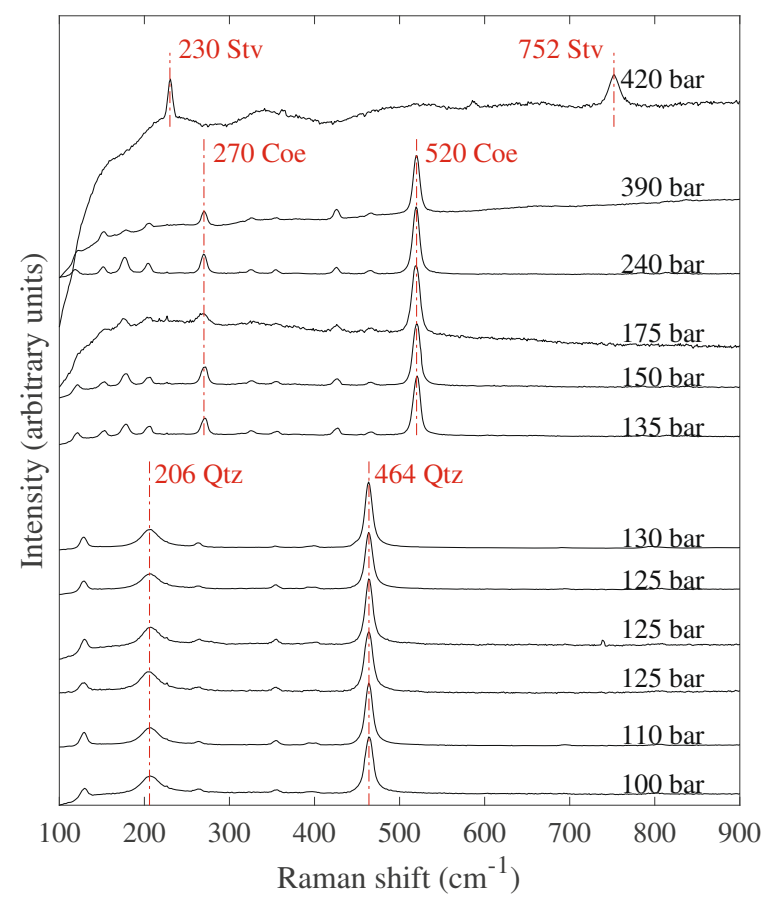

Fig. 5 The Raman spectra from recovered $\mathrm{SiO}_{2}$ samples obtained from the experiments listed in Table 1 . Characteristic peaks of quartz, coesite and stishovite are labelled by the abbreviations 'Qtz', 'Coe' and 'Stv', respectively

variations are consistent with the $<20{ }^{\circ} \mathrm{C}$ variations in the central $3 \mathrm{~mm}$ of the assembly measured by van Westrenen et al. [44] using spinel growth kinetics in a similar assembly. The modelled temperature drops by $90{ }^{\circ} \mathrm{C}$ from $\mathrm{z}=1.5 \mathrm{~mm}$ to $\mathrm{z}=2.5 \mathrm{~mm}$, illustrating the importance of placing the thermocouple junction close to the sample container. In practice, the hard 4-bore $\mathrm{Al}_{2} \mathrm{O}_{3}$ tube holding the thermocouple wires is usually effectively pressing the thermocouple junction onto the graphite bucket while it is pressurized by the WC anvils, which ensures that the junction is usually at or very close to the boundary between the sample container and $\mathrm{Al}_{2} \mathrm{O}_{3}$ tubing. This implies that the temperature read-out is usually fairly accurate, provided that the total length of the sample and container combination is below $3 \mathrm{~mm}$ in $\mathrm{z}$-direction.

An additional error on the temperature measurement arises from the pressure effect on the electromotive force induced by the Seebeck effect that is not taken into account (the ASTM E230/E230M standard is calibrated at ambient pressures). This pressure effect on the thermocouple is expected to be small at temperatures below $1500{ }^{\circ} \mathrm{C}$ and is universally neglected in high-pressure setups around the world [45].

Table 1 shows that a significant number of experiments experienced thermocouple failure. This is particularly the case for the earlier experiments (numbered MA25 and lower), of which $60 \%$ had failed thermocouples. In these early experiments, we used thermocouple wires of $0.018 \mathrm{~mm}$ diameter. The later experiments, numbered MA26 and beyond, were performed with slightly thicker thermocouple wires of $0.025 \mathrm{~mm}$ thickness, which help prevent thermocouple failures (28\% thermocouple failure). We are currently taking additional measures to further reduce thermocouple failures. 


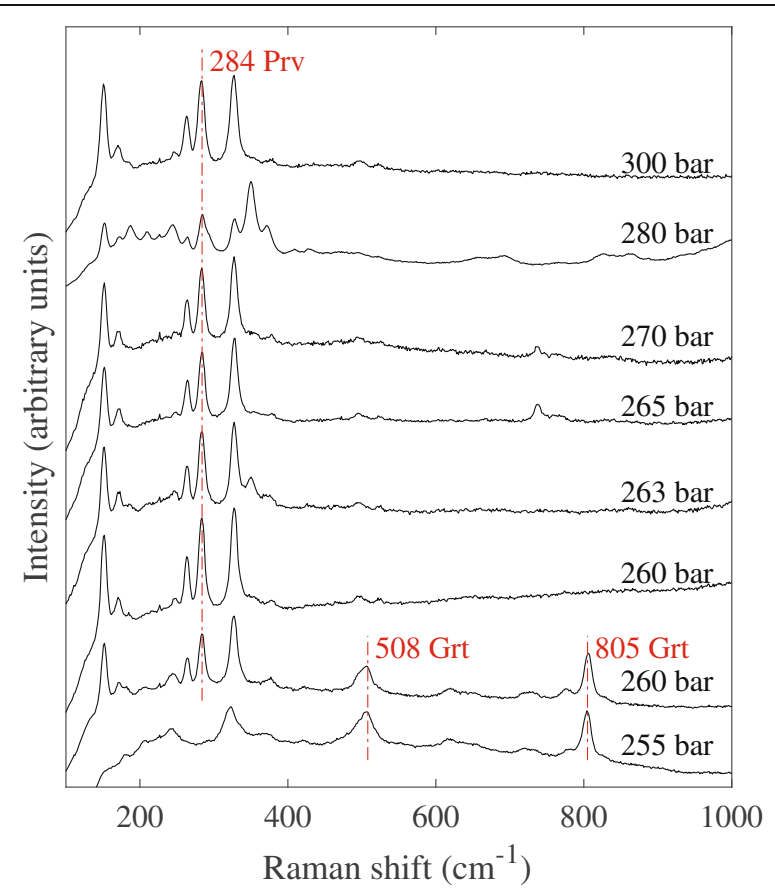

Fig. 6 The Raman spectra from recovered $\mathrm{CaGeO}_{3}$ samples obtained from the experiments listed in Table 1. Characteristic peaks of garnet-structured and perovskite-structured polymorphs are labelled by the abbreviations 'Grt' and 'Prv', respectively

In experiments where thermocouple readout failed, the sample temperature is estimated by the relation between power and temperature as recorded in comparable experiments with surviving thermocouples (Fig. 9). The power-temperature relation varies per experiment for several reasons. First, while our calibration work progressed, we were increasingly successful in machining thinner graphite heaters which heat more efficiently. This is reflected in Fig. 9 by the lower temperature in the MA6, MA7, and MA11 experiments compared to the MA13, MA15 and MA16 experiments at similar powers. Second, heating is less efficient at higher pressures, which is reflected by the lower temperature in the experiments from MA26 to MA32 at similar power compared

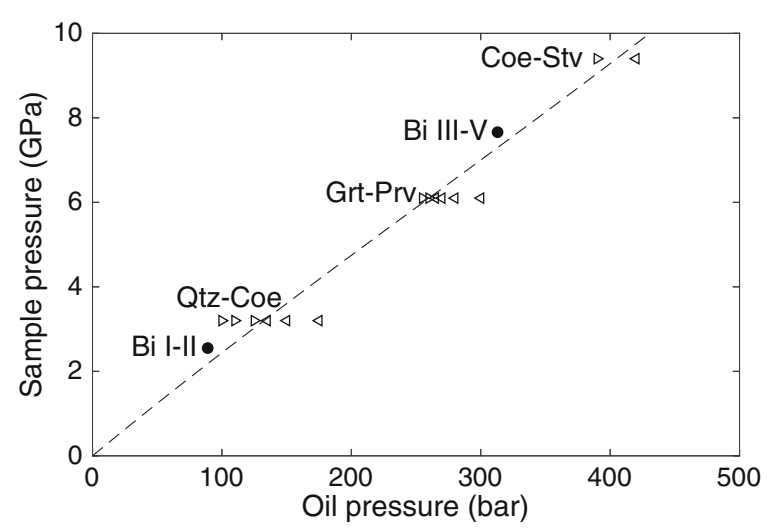

Fig. 7 The pressure calibration curve which relates the oil pressure in the oil vessel to the attained sample pressure for temperatures at room temperature $(\mathrm{Bi})$ and at $\sim 1300{ }^{\circ} \mathrm{C}$. The dashed line is obtained from a spline interpolation through the high-temperature calibration points 
Table 2 A list of points on the calibration curve

\begin{tabular}{ll}
\hline Oil pressure (bar) & Sample pressure (GPa) \\
\hline 21 & 0.5 \\
41 & 1 \\
62 & 1.5 \\
83 & 2 \\
104 & 2.5 \\
125 & 3 \\
146 & 3.5 \\
168 & 4 \\
190 & 4.5 \\
212 & 5 \\
234 & 5.5 \\
257 & 6 \\
279 & 6.5 \\
301 & 7 \\
323 & 7.5 \\
345 & 8 \\
367 & 9.5 \\
389 & 9 \\
410 & 10 \\
431 & 5 \\
\hline
\end{tabular}

to the MA13, MA15 and MA16 experiments. We took these effects into consideration when we estimated the temperature of experiments with failed thermocouples. The resulting errors on these estimates are likely on the order of \pm 150 degrees. The power used in experiment MA28 is exceptionally high in relation to those of other experiments at similar pressures, in particular in relation to experiment MA23 that was performed at identical pressure. We suspect that the temperature measurement of the MA28 experiment was in error by $\sim 200{ }^{\circ} \mathrm{C}$ (too low), potentially as a result of a rare displacement of the thermocouple junction away from the sample container. This may have placed MA23 at the garnet-perovskite boundary and the hotter MA28 in the stability field of perovskite.

\section{Pressure errors}

The phase transitions used for the high-temperature quench experiments are relatively insensitive to temperature. We estimate that the temperature error propagates to an error in the pressure calibration of below 0.2 GPa.

The largest error of our pressure calibration originates from uncertainties in the pressure of the phase transitions themselves. These errors accumulate with increasing pressure because fully hydrostatic experiments (when samples pressure can be directly calculated by the amount of applied force) can only be performed at pressures below $3 \mathrm{GPa}$, as most appropriate liquid pressure media will accumulate stresses at higher pressures (e.g. [22]). A pressure standard for experimental studies for higher pressure phase relations relies on the extrapolation of crystalline behavior at low pressures using 

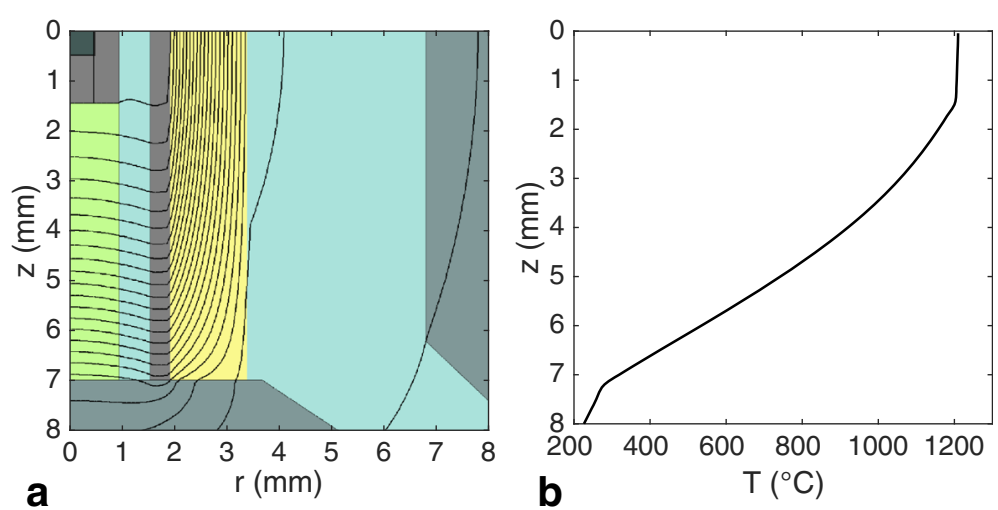

Fig. 8 a The temperature distribution in the assembly, as modelled with the numerical model of Hernlund et al. [43]. Constant colour areas are indicative of sample (black), graphite (grey), $\mathrm{Al}_{2} \mathrm{O}_{3}$ thermocouple tubing (green), $\mathrm{MgO}$ (cyan), $\mathrm{Zr}_{2} \mathrm{O}_{3}$ (yellow) and WC cubes (darkish cyan). Black contours lines represent isotherms separated by 50 degree intervals, with the $1200{ }^{\circ} \mathrm{C}$ isotherm located closest to the sample (at $\mathrm{z}=1.5 \mathrm{~mm}$ and $r=0 \mathrm{~mm}$ ). $\mathbf{b}$ The modelled temperature profile along the assembly's axis (the $r=0$ line)

thermodynamic formulations (equations of state). The errors on these extrapolations increase with increasing pressure. As a result, the standard error on the phase transitions used in this study are below $\pm 0.1 \mathrm{GPa}$ for the Bi I-II transition, $\pm 0.2 \mathrm{GPa}$ for the quartz-coesite transition in $\mathrm{SiO}_{2}$ and the garnet-perovskite transition in $\mathrm{CaGeO}_{3}$, $\pm 0.3 \mathrm{GPa}$ for the Bi III-V transition and $\pm 0.4 \mathrm{GPa}$ for the coesite-stishovite transition in $\mathrm{SiO}_{2}$.

Another error originates from the identification of and interpolation between the calibration points. This error is difficult to quantify, but likely does not exceed $0.3 \mathrm{GPa}$. The total error on the pressure calibration grows from $\pm 0.2 \mathrm{GPa}$ at 100 bars to $\pm 0.6 \mathrm{GPa}$ at 400 bars.

\section{Conclusions}

The 18/11 assembly as calibrated in this study can expose cubic millimeter sized samples to pressure and temperature conditions that exist in deep planetary interiors (down to a depth of $\sim 300 \mathrm{~km}$ in Earth, $\sim 650 \mathrm{~km}$ in Mercury and $\sim 750 \mathrm{~km}$ in Mars).

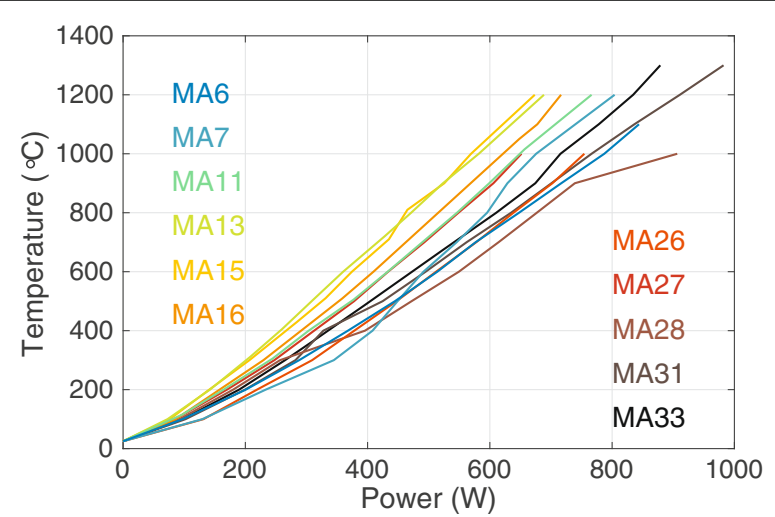

Fig. 9 The relation between electrical power and thermocouple temperature as recorded for the experiments in this study (Table 1). Power and temperature are recorded at every subsequent 100 degree interval and linearly interpolated 
The apparatus can be used to test high-pressure phase relations predicted by ab initio and thermodynamic calculations (e.g. $[15,16]$ ), and to give insights into the origin of surface material that is thought to originate from great depths. These types of experimental constraints on deep planetary matter are complementary to other approaches currently adopted in interior planetary modeling studies ([11-14]). In the future, a smaller $8 \mathrm{~mm} / 3 \mathrm{~mm}$ OEL/TEL assembly can be used in the same press expanding the accessible pressure range to a maximum of $\sim 25 \mathrm{GPa}$ (e.g. [21]).

Abbreviations

Coe: Coesite; Grt: Garnet; OEL: Octahedral edge length; Prv: Perovskite; Qtz: Quartz; Stv: Stishovite; TEL: Truncated edge length

\section{Acknowledgements}

We thank Yingwei Fei of the Geophysical Laboratory at the Carnegie Institution for Science in Washington DC, and Stephan Klemme and Arno Rorhbach from the Universität Münster for providing assembly parts for experiments at times that we were in need.

\section{Funding}

This research was funded by a Netherlands Space Office User Support Programme Space Research grant (ALW-GO/1238) to W.v.W. and the Belgian Science Policy Office (contract BR/143/A2/COME-IN). Europlanet 2020 RI has received funding from the European Union's Horizon 2020 research and innovation programme under grant agreement No 654208.

Availability of data and materials

Data is available upon request to the corresponding author.

\section{Authors' contributions}

JSK has done most of the writing and figures of this paper, followed by SML and WVW. JSK and SML have performed most of the experiments in this study. RS and DMvH have constructed the necessary oil-pumping system and its regulations. WvdP has installed the necessary electricity system and its regulations. NR has been involved in the early stages of the installation of this device. RJvdG has helped moving the 800-ton press and manufactured crucial assemblyparts. ESS has performed a few experiments and was the line of communication to the University of Münster for requesting assembly-parts at times that we were in need. WVW, JSK and SML have managed the whole operation from installation to calibration of the press. All authors read and approved the final manuscript.

\section{Competing interests}

The authors declare that they have no competing interests.

\section{Publisher's Note}

Springer Nature remains neutral with regard to jurisdictional claims in published maps and institutional affiliations.

\section{Author details}

${ }^{1}$ Faculty of Science, Vrije Universiteit Amsterdam, Amsterdam, the Netherlands. ${ }^{2}$ Department of Earth Sciences, Indian Institute of Technology Roorkee, Roorkee, India.

Received: 16 April 2018 Accepted: 21 June 2018

Published online: 04 July 2018

\section{References}

1. Klaver M, de Roever EWF, Nanne JAM, Mason PRD, Davies GR (2015) Charnockites and UHT metamorphism in the Bakhuis Granulite Belt, western Suriname: evidence fort wo separate UHT events. Precambrian Res 262:1-19 https://doi.org/10.1016/j.precamres.2015.02.014

2. Klaver M, Carey S, Nomikou P, Smet I, Godelitsas A, Vroon P (2016) A distinct source and differentiation history for Kolumbo submarine volcano, Santorini volcanic field, Aegean arc. Geochem Geophys Geosyst 17:3254-3273 https://doi.org/10.1002/2016GC006398

3. Koornneef JM, Gress MU, Chinn IL, Jelsma HA, Harris JW, Davies GR (2017) Archean and Proterozoic diamond growth from contrasting styles of large-scale magmatism. Nat Commun 8:1-8 https://doi.org/10.1038/s41467-01700564-x

4. Nikogosian I, Ersoy Ö, Whitehouse M, Mason PRD, de Hoog JCM, Wortel R, van Bergen MJ (2016) Multiple subduction imprints in the mantle below Italy detected in a single lava flow. Earth Planet Sci Lett 449:12-19 https://doi.org/10.1016/j.epsl.2016.05.033

5. Hacker BR, Gerya TV, Gilotti JA (2013) Formation and exhumation of ultrahigh-pressure terranes. Elements 9:289293 https://doi.org/10.2113/gselements.9.4.289

6. Rawlinson N, Pozgay S, Fishwick S (2010) Seismic tomography: a window into deep earth. Phys Earth Planet Inter 178:101-135 https://doi.org/10.1016/j.pepi.2009.10.002 
7. Vissers RLM, van Hinsbergen DJJ, van der Meer DG, Spakman W (2016) Cretaceous slab break-off in the Pyrenees: Iberian plate kinematics in paleomagnetic and mantle reference frames. Gondwana Res 34:49-59 https://doi.org/ 10.1016/j.gr.2016.03.006

8. de Wit RWL, Trampert J (2015) Robust constraints on average radial lower mantle anisotropy and consequences for composition and texture. Earth Planet Sci Lett 429:101-109 https://doi.org/10.1016/j.epsl.2015.07.057

9. Garcia RF, Gagnepain-Beyneix J, Chevrot S, Lognonné P (2011) Very preliminary reference moon model. Phys Earth Planet Int 188:96-113 https://doi.org/10.1016/j.pepi.2011.06.015

10. Weber RC, Lin PY, Garnero EJ, Williams Q, Lognonné P (2011) Seismic detection of the lunar core. Science 331 : 309-312 https://doi.org/10.1126/science.1199375

11. Knibbe JS, van Westrenen W (2015) The interior configuration of planet mercury constrained by moment of inertia and planetary contraction. J Geophys Res Planets 120:1904-1923 https://doi.org/10.1002/2015JE004908

12. Orué HMJ, Vermeersen BLA (2016) Tides on Jupiter's moon Ganymede and their relation to its internal structure. Neth J Geosci 95:191-201 https://doi.org/10.1017/njg.2015.23

13. Rivoldini A, Van Hoolst T (2013) The interior structure of mercury constrained by the low-degree gravity field and the rotation of mercury. Earth Planet Sci Lett 377-378:62-72 https://doi.org/10.1016/j.epsl.2013.07.021

14. Root BC, Ebbing J, van der Wal W, England RW, Vermeersen LLA (2016) Comparing gravity-based to seismicderived lithospheric densities: a case study of the British Isles and surrounding areas. Geophys J Int 208:1796-1810 https://doi.org/10.1093/gji/ggw483

15. Cottenier S, Probert MIJ, Van Hoolst T, Van Speybroack V, Waroquier M (2011) Crystal structure prediction for iron as inner core material in heavy terrestrial planets. Earth Planet Sci Lett 312:237-242 https://doi.org/10.1016/j.epsl.2011.09.045

16. Jacobs MHG, Schmid-Fetzer $R$, van den Berg AP (2017) Phase diagrams, thermodynamic properties and sound velocities derived from a multiple Einstein method using vibrational densities of states - an application to $\mathrm{MgO}-\mathrm{SiO}_{2}$. Phys Chem Miner 44:43-62 https://doi.org/10.1007/s00269-016-0835-4

17. McDade P, Wood BJ, van Westrenen W, Brooker R, Gudmundsson G, Soulard H, Najorka J, Blundy J (2002) Pressure corrections for a selection of piston-cylinder cell assemblies. Min Mag 66:1021-1028 https://doi.org/10.1180/ 0026461026660074

18. Liebermann RC (2011) Multi-anvil, high pressure apparatus: a half-century of development and progress. High Pressure Res 31:493-532 https://doi.org/10.1080/08957959.2011.618698

19. Walker D, Carpenter MA, Hitch CM (1990) Some simplifications to multianvil devices for high pressure experiments. Am Mineral 75:1020-1028 http://ammin.geoscienceworld.org/content/75/9-10/1020

20. Kawai N, Endo S (1970) The generation of ultrahigh hydrostatic pressures by a split sphere apparatus. Rev Sci Instrum 41:1178-1181 https://doi.org/10.1063/1.1684753

21. Leinenweber KD, Tyburczy JA, Sharp TG, Soignard E, Diedrich T, Petuskey WB, Mosenfelder JL (2012) Cell assemblies for reproducible multi-anvil experiments (the COMPRES assemblies). Am Mineral 97:353-368 https:// doi.org/10.2138/am.2012.3844

22. Decker DL, Basset WA, Merrill L, Hall HT, Barnett JD (1972) High-pressure calibration: a critical review. J Phys Chem Ref Data 1:773-836 https://doi.org/10.1063/1.3253105

23. Akaogi M, Navrotsky A (1984) The quartz-coesite-stishovite transformations: new calorimetric measurements and calculation of phase diagrams. Phys Earth Planet Int 35:124-134 https://doi.org/10.1016/0031-9201(84)90013-X

24. Bohlen SR, Boettcher AL (1982) The quartz - coesite transformation: a precise determination and the effects of other components. J Geophys Res Solid Earth 87:7073-7078 https://doi.org/10.1029/JB087iB08p07073

25. Bose K, Ganguly J (1995) Quartz-coesite transition revisited: reversed experimental determination at $500-1200{ }^{\circ} \mathrm{C}$ and retrieved thermochemical properties. Am Mineral 80:231-238 https://doi.org/10.2138/am-1995-3-404

26. Boyd FR, England JL (1967) The quartz-coesite transition. J Geophys Res 65:749-756 https://doi.org/10.1029/ JZ065i002p00749

27. Coes L (1953) A new dense crystalline silica. Science 118:131-132 https://doi.org/10.1126/science.118.3057.131

28. Mirwald PW, Massonne HJ (1980) The low-high quartz and quartz-coesite transition to 40 kbar between $600^{\circ}$ and $1600^{\circ} \mathrm{C}$ and some reconnaissance on the effect of $\mathrm{NaAlO}_{2}$ component on the low quartzcoesite transition. J Geophys Res Solid Earth 85:6983-6990 https://doi.org/10.1029/JB085iB12p06983

29. Weaver JS, Chipman DW, Takahashi T (1979) Comparison between thermochemical and phase stability data for the quartz-coesite-stishovite transformations. Am Mineral 64:604-614. https://pubs.geoscienceworld.org/msa/ ammin/article-abstract/64/5-6/604/41027/comparison-between-thermochemical-and-phase

30. Akimoto $\mathrm{S}$ (1972) The system $\mathrm{MgO}-\mathrm{FeO}-\mathrm{SiO}_{2}$ at high pressures and temperatures - phase equilibria and elastic properties. Tectonophysics 13:161-187 https://doi.org/10.1016/0040-1951(72)90019-4

31. Akimoto S, Syono Y (1969) Coesite-Stishovite transition. J Geophys Res 74:1653-1659 https://doi.org/10.1029/ JB074i006p01653

32. Stishov SM, Popova SV (1961) A new dense modification of silica. Geokimiya 10:837-839

33. Yagi T, Akimoto S (1976) Direct determination of coesite-stishovite transition by in-situ X-ray measurements. Tectonophysics 35:259-270 https://doi.org/10.1016/0040-1951(76)90042-1

34. Zhang J, Li B, Utsumi W, Liebermann RC (1996) In situ X-ray observations of the coesite-stishovite transition: reversed phase boundary and kinetics. Phys Chem Miner 23:1-10 https://doi.org/10.1007/BF00202987

35. Zhang J, Liebermann RC, Gasparik T, Harzberg CT, Fei Y (1993) Melting and subsolidus relations of SiO2 at 9-14 GPa. J Geophys Res 98:19785-19793 https://doi.org/10.1029/93JB02218

36. Ono S, Kikegawa T, Higo Y (2011) In situ observation of a garnet/perovskite transition in $\mathrm{CaGeO}_{3}$. Phys Chem Miner 38:735-740 https://doi.org/10.1007/s00269-011-0446-z

37. Prewitt CT, Sleight AW (1969) Garnet-like structures of high-pressure cadmium germanate and calcium germanate. Science 163:386-387 https://doi.org/10.1126/science.163.3865.386

38. Ringwood AE, Major A (1967) Some high-pressure transformations of geophysical significance. Earth Planet Sci Lett 2:106-110 https://doi.org/10.1016/0012-821X(67)90109-4

39. Ringwood AE, Seabrook M (1963) High-pressure phase transformations in germinate pyroxenes and related compounds. J Geophys Res 68:4601-4609 https://doi.org/10.1029/JZ068i015p04601 
40. Ross NL, Akaogi M, Navrotsky A, Susaki J, McMillan P (1986) Phase transitions among the CaGeO3 polymorphs (wollastonite, garnet, and perovskite structures): studies by high-pressure synthesis, high-temperature calorimetry, and vibrational spectroscopy and calculation. J Geophys Res Solid Earth 91:4685-4696 https://doi.org/10.1029/ JB091iB05p04685

41. Susaki J, Akaogi M, Akimoto S, Shimomura O (1985) Garnet-perovskite transformation in CaGeO3: in-situ X-ray measurements using synchrotron radiation. Geophys Res Lett 12:729-732 https://doi.org/10.1029/ GL012i010p00729

42. Durben DJ, Wolf GH, McMillan PF (1991) Raman scattering of the high-temperature vibrational properties and stability of CaGeO3 perovskite. Phys Chem Min 18:215-223 https://doi.org/10.1007/BF00202573

43. Hernlund J, Leinenweber K, Locke D, Tyburczy JA (2006) A numerical model for steady-state temperature distributions in solid-medium high-pressure cell-assemblies. Am Mineral 91:295-305 https://doi.org/10.2138/am 2006.1938

44. van Westrenen W, van Orman JA, Watson H, Fei Y, Watson EB (2003) Assessment of temperature gradients in multianvil assemblies using spinel layer growth kinetics. Geochem Geophys Geosyst 4:1036 https://doi.org/10. 1029/2002GC000474

45. Li J, Hadidiacos C, Mao HK, Fei Y, Hemley RJ (2002) Behavior of thermocouples under high pressure in a multianvil apparatus. High Pressure Res 23:389-401 https://doi.org/10.1080/0895795031000088269

Submit your manuscript to a SpringerOpen ${ }^{\circ}$ journal and benefit from:

- Convenient online submission

- Rigorous peer review

Open access: articles freely available online

- High visibility within the field

Retaining the copyright to your article

Submit your next manuscript at $\gg$ springeropen.com 